\title{
MYRIAM DUROCHER
}

\author{
University of Montreal, Canada
}

MYRIAM.DUROCHER@UMONTREAL.CA

\section{Mediatization Studies and Cultural Studies: A Possible Dialogue for Further Critical Analysis?}

\begin{abstract}
Over the last decades, it has been possible to observe an increasing number of studies that claim the impossibility to dissociate changes that occur within media, culture and society. Mediatization theories, particularly those developed in Scandinavian countries, and American approach to cultural studies utilize interesting tools and conceptual material to think about the transformations that arise through the social field. Both encourage questioning the power relations and struggles that inform those transformations. However, the manners in which they conceive and use "culture" and "media" as conceptual tools for analysis differs, offering multiple and diverging ways to study and question objects, phenomena and processes.

These two approaches do not appear as irreconcilable and could be used in dialogue as a way to see how they can possibly complement each other by, for example, enriching their mutual understanding of power and, therefore, their critical character. This article highlights points of tension and convergence between cultural studies and mediatization studies. It explores cultural studies' focus on (cultural) practices as privileged spaces for power relations analysis and their ongoing negotiations by and through media. This approach may resonate or complement Couldry's [2004] proposal for a paradigm of media as practice "to help us address how media are embedded in the interlocking fabric of social and cultural life" [p. 129].

This dialogue between mediatization theories and cultural studies is being put to the forefront with the hope it may allow further discussions and relevant theoretical avenues for critical research located within both fields. Thinking of this possible interplay lets us foresee the possibility of questioning objects, processes and phenomena from a critical perspective in a context produced and characterised by the omnipresence of media. It would allow researchers to question the power struggles that are negotiated through practices themselves, taking into account that most of them are made by, with or within media.
\end{abstract}

Keywords: mediatization studies; cultural studies; media; power; culture; practices 


\section{Introduction}

Over the last decades, it has been possible to observe an increasing amount of research aiming to conceptualize the interrelation between media, culture and society. The impossibility to dissociate changes which occur in each of these areas of life serves as common assumption for the development of mediatization theories particularly in Scandinavian countries, of American and British configurations of cultural studies and of theories inspired by the concept of media cultures [Maigret 2009] in France. Emerging from different disciplinary traditions as well as national ones, these fields have not been or, too little, put in dialogue. This article aims to pursue the dialogue between cultural studies and mediatization theories initiated by, among other theorists,akeynote speaker John Storey during the Critical Mediatization Research Conference (held in Bremen, August 2016 ${ }^{1}$ ). This theoretical and conceptual exploration is motivated by the impression that both fields could bring relevant theoretical and empirical contributions to each other, conveying new possible avenues for critical research and further discussions. Emerging at the same time and sharing similar interests and interrogations for culture and media, some elements of media cultures' conceptualisation will be added to the present reflection. It will be exposed how its use seems to be less relevant for the study of cultural and media transformations than what cultural studies and mediatization theories may offer.

These two fields bring interesting tools and conceptual material to think about the transformations that occur within the social field, each of them questioning power relations and struggles that inform those transformations. However, the manners in which they conceive and use "culture" and "media" as conceptual tools for analysis differs, offering multiple and diverging ways to study and question objects, phenomena and processes. These two approaches do not appear as irreconcilable and could be used in dialogue as a way to see how they can possibly complement each other. On the one hand, this dialogue may allow to enrich the critical character of mediatization theories; on the other hand, it may improve media analysis within cultural studies, adding to their conception and mobilisation of media to understand culture, practices and processes which take part in it, in the context of a society crossed and informed by the omnipresence of media. The body of this reflexive work is located within a critical perspective: critical in this context does not mean taking into account the interrelations between communicative, social and cultural change to criticize or categorize what should be conceived as good or bad. Rather, it means considering power in its Foucaldian sense, aiming to uncover the taken-for-granted familiarity and unquestioned character of the practices we commonly accept.

Some elements of the present conceptual and theoretical reflection have also been presented and discussed during the Conference "Critical Mediatization Research. Power, Inequality and Social Change in a Mediatized Age" held in Bremen, August 30, 2016 to September 1, 2016. 
"Cultural studies" and "mediatization theories" are umbrella terms that refer to a variety of methodological and theoretical approaches - neither field is homogeneous. Hence, it is necessary to situate the reflection within or vis-à-vis both fields before engaging in any dialogue. This will specify the position from which each field addresses culture and society through non-media-centric approaches. To do so, points of tension and convergence will be highlighted between cultural studies and mediatization theories in regard to their conceptual definition and analytical mobilisation of "culture" and "media" by means of an overview of their diverging, yet no entirely irreconcilable, conceptualisations of power.

\section{Definition and mobilization of "culture" within American developments of cultural studies}

As an interdisciplinary field composed by a multiplicity and a diversity of approaches, methods and objects of research, cultural studies are characterised by the heterogeneity of perspectives it inspires and develops [Cervulle and Quemener 2015]. It has traveled and has been developed differently in areas and territories that have favored its emergence [Neveu 2008].The majority of cultural studies-oriented projects share the objective of analyzing the power struggles that cut across, inform and contribute to producing culture. The field of study aims to expose how individuals are "[...] empowered and disempowered by the particular structures and forces that organize their everyday lives in contradictory ways, and how their (everyday) lives are themselves articulated to and by the trajectories of economic, social, cultural, and political power" [Grossberg 2010, pp. 8-9].

This definition of culture is inspired by Raymond Williams [1981] for whom culture is "ordinary", which means that the significations that are created, shared and made effective through it contribute to the production of practices that compose it. It is by culture that the significant system, by which social order is (re)produced and lived, is constituted. Stuart Hall [1980] added to this definition that it is by culture that significations and values relative to a social group are defined, emerging from and within a given socio-historical context, and expressed by living experience of practice. He characterises this definition of culture as "anthropologic" as it tends to be understood from its constitutive practices and, more specifically, by the relations that organise it:

2 It is important to note that "media" is not defined here as limited to media institutions as producers and diffusers of information, nor as technological means. Following Friedrich Krotz's definition, it refers to technologies that allow communication at a distance, always linked to communicative practices, and operating "as a societal institution, as an organizational machine and a way of setting content in a scene, and as a space of experience of a recipient" [Krotz 2009, p. 23]. 
The analysis of culture is, then, "the attempt to discover the nature of the organization which is the complex of these relationships". It begins with "the discovery of patterns of a characteristic kind". One will discover them, not in the art, production, trading, politics, the raising of families, treated as separate activities, but through "studying a general organization in a particular example" [p. 61]. Analytically, one must study "the relationships between these patterns". The purpose of the analysis is to grasp how the interactions between all these practices and patterns are lived and experienced as a whole, in any particular period. This is its "structure of feeling" [Williams [1961], quoted in Hall 1980, pp. 59-60].

Through the exploration of the individual lived experience of the practice and its linkage with that of the collective, "[...] we discover that we are analysing, as two forms of the same process, its active composition and its conditions of composition, and in one way or another, it is a complex set of active relations in extension" [free translation, Williams 2010, pp. 57-58].

This present work of reflection is largely inspired by conceptual definitions and analysis methods associated with the development of the field in America. James Carey [1989] and Lawrence Grossberg [1996] largely contributed to the development of cultural studies in America. For instance, they worked on the theorisation of the relation between culture and power, with the premise that power is deployed and acts within culture itself. Culture is then defined, used and analysed as a whole set of "resources, techniques, tools, specific knowledges, programs, technologies, aimed at managing populations, aimed at changing the habits of conduct, feeling, expression, and thought of a population" [Grossberg 2010, p. 172]. Culture, as defined here, operates within different dimensions and location, allowing the production of practices which are, at the same time, the materialization and the location of power struggles. By analysing culture, we are analysing what is structuring daily and social life and what meanings, values and significations are embodied within those practices and their articulation.

This kind of analysis of practice is embedded within a set of relations that actualize, organize and allow it to suggest a rupture with a form of analysis consisting in isolating the object to unravel its constitutive elements. It enables questioning what allows its existence, its condition of possibility. This conception of practice as constitutive of culture and as not being imposed over or the fruit of a dominant entity is corresponding to the development of cultural studies influenced by the poststructuralist approach. More precisely, it is in line with the body of work of Michel Foucault and its conception of power as productive and circulating within the social field (this definition of power as produced within culture will be addressed later in this article). Such an understanding of culture as constituted by and within practice situate the media as one of the sites (but not the only one) of production, diffusion and exercise of power. 


\section{An analysis of media in its interrelation with culture and society}

Framing the media as taking part in the constitution of culture and advocating for its analysis within it rather than isolating is coherent with Williams' definition of culture. The latter is defined as not being dominated by only one mode of production or a dominant entity, but rather needed to be understood by the analysis of its constitutive practices, one of which is the media. This understanding of media practices as produced by and embedded in a larger set of relations is characteristic of the development of cultural studies in American academic field. Researchers whose body of work is rooted within this approach advocate an analysis of cultural (and media) practices as not being restricted to the object (such as a media product, for example) itself, but rather enlarged to consider the broader power struggles that are at play in its production. It also echoes the critiques of researchers such as David Hesmondhalgh [2008] who has criticized the near absence of consideration for the production context of cultural products characteristic of original British configurations of cultural studies. For the theorist, this lack prevents adequate understanding of power struggles that are negotiated through the production of media products and, therefore, the contextual conditions and transformations occurring within the social field.

The conceptualisation of culture as processual and as formed with and within the media is a good starting point for a possible dialogue between cultural studies and mediatization theories. The latter is still at its early stage of development. Perspectives multiplies and definitions are still negotiated [Sawchuck 2013]. Three discernible approaches are presented by Knut Lundby [2014], amongst other theoreticians contributing to the development of the field, which are designated as the cultural, material and institutional perspectives. All share a common understanding that society, as molded by the omnipresence of media, cannot be understood by the only effects of their presence, but rather by the interrelation "between the change of media and communication, on the one hand, and the change of (fields of) culture and society, on the other hand" [Hepp, Hjarvard and Lundby 2015, p. 7]. Media are not seen as the "driving forces" of these changes as other processes "[...] might find their expression in media and communications" [ibid]. Hence, this approach aims to question the interrelation of media, culture and society without undertaking a causal understanding of media's role in transformational processes. This non-deterministic approach is typical of analysis conducted from the perspective of mediatization theories: "Being "media-centric « is a one-sided approach to understanding the interplay between media, communications, culture, and society, whereas being "media-centered « involves a holistic understanding of the various intersecting social forces at work at the same time as we allow ourselves to have a particular perspective and emphasis on the role of the media in these processes" [ibid, p. 3].

As this exploration work tries to question, on the one hand, the communicative construction of "reality" that manifests itself through media processes and, on the 
other hand, how the transformations occurring with and within media contribute to the constitution of the socio-cultural context, it will mainly be anchored within the cultural branch of mediatization theories, mainly developed and promoted by Andreas Hepp [2012]. This approach shares similar interests with cultural studies in its aim to grasp an understanding of the interrelation processes that occur and co-inform media and cultural transformations. As Göran Bolin [2014] stated, the institutional approach has adopted something more of a transmission perspective, rather than a ritual one as developed by researchers affiliated to the cultural approach. In doing so, the institutional perspective gives media an institutional status, their logic being seen as penetrating and modulating the social field. As for the material approach, it is more concerned by how the materiality and the technical aspects of the media are "texturing" everyday life [Lundby 2014]. Hence, it is less concerned by how it is embedded within cultural processes and how it embodies and reifies certain interactional and communicational processes, as it is investigated by the cultural perspective:

Here we come back to the point already raised above, that media as technologies permit specific relations of communicative power to be rendered enduring through their reification. The traditional mass media entrench their communicative networks by their embodiment in broadcasting institutions, radio masts, cables, and so on, and this in turn entrenches the power of their communicative structures [Hepp 2013, p. 88].

While the institutional approach aims to understand how the media logic comes to modulate the development of other institutions (such as religion or politics) [Hjarvard 2013; Hjarvard and Petersen 2013], the cultural approach is much more concerned about how the omnipresence of media modulates social interaction and communication [Hepp 2013]. Inspired by Jésus Martín-Barbero [2002], Hepp [2012] conceives mediatization as taking into account the mediation that occurs within the socio-cultural context and that contributes to modulating the media and the communicative process: "[...] mediatization seeks to capture the nature of the interrelationship between historical changes in media communication and other transformational processes. Hence mediatization presumes mediation through media communication" [Hepp 2013, p. 38]. This conception of media, as being constituted by and within the context and the practices that participate in its production, may be seen as a convergence point that relates to cultural studies.

\section{Media as a cultural form}

Within cultural studies as described earlier, the media is conceived as being constituted by and within the context and the practices that participate in its production. It cannot be isolated and taken as the main tool or object for analysis; it must be con- 
sidered at the intersection of a conjuncture of practices, relations, locations, always subjected to changes, negotiations and redefinitions. This approach is taking away from the analysis of the media in terms of "effects", relocating it as one of the many sites of the production of the social field:

[...] cultural studies in whatever form it survives offers the real advantage of abandoning an outmoded philosophy of science (maybe even getting rid of the philosophy of science altogether) and centering the mass media as a site (not a subject or a discipline) on which to engage the general question of social theory: How is it, through all sorts of change and diversity, through all sorts of conflicts and contradictions, that the miracle of social life is pulled off, that societies manage to produce and reproduce themselves? [Carey 1989, p. 83].

Williams' analysis of the television's developments, seen as a technology as much as a cultural form, differed from traditional studies on audiences or texts largely done within cultural studies. It offered to get interest in cultural, political, economic, etc., conditions of the development of the technology, leaving room for an understanding of the medium in its interpretation and usage, as a cultural form:

The technology would be seen, that is to say, as being looked for and developed with certain purposes and practices already in mind. At the same time the interpretation would differ from symptomatic technology in that these purposes and practices would be seen as direct: as known social needs, purposes and practices to which the technology is not marginal but central [Williams 1975, p. 7].

The media is then analysed as entangled with a whole set of contextual practices operating by and through power struggles, these not only limited to the technology itself. Inspired by Williams, Krotz and Hepp [2011] have proposed an understanding of the media as a cultural form: "[...] Williams has demonstrated that media today consist on the one hand of technologies, and on the other hand function as social forms. This means that we cannot reduce media to questions of technology or the social but must reflect on how both are interwoven" [Krotz and Hepp 2011, p. 143]. For Hepp [2013], the media is being institutionalised and reified in contextual circumstances that materialize cultural forces that are at play within the social field. Culture is seen as being produced within communication and interaction. Here, "culture" is inspired by Hall's definition as it refers to the accumulation of discursive formations and classificatory systems that contribute to producing meanings [Hepp 2013 , p. 5]. Hence, "media cultures" are cultures where significations production is mediated by technological means that, by the reification and institutionalisation of particular forms of communication rather than others, are crystalizing certain forms of communicative power, for a specific socio-cultural context. Therefore, the "molding" power of the media is (re)produced and lived within interaction and 
communicative practices constitutive of culture, by which individuals are making sense and experiencing "reality".

We must note that the notion of "culture" has been defined and mobilized in various ways within mediatization theories. Some will refer to forms which could be described as more "material" such as cultural institutions, artefacts or practices that are commonly described as "the" culture (as it is the case within material and institutional approaches, for example [see Hjarvard 2008]. For instance, in some analyses inspired by the institutional perspective, "culture" seems to be referring to the definition elaborated by Williams. However, there is no consideration for power as it might be negotiated throughout the daily practices that constitute it. Also, this conception of "culture" as it is used in many papers from the mediatization field does not seem to draw a clear and distinctive line from the conceptualization of "society". This different conceptualisation and use of "culture" represent an important tension point between cultural studies and mediatization theories. It also consists in a good starting point for a possible dialogue between the fields. The definition and mobilization of "culture" by the cultural studies offer a complement to mediatization theories. As Couldry proposed, it could be useful for the development of a perspective "of practice to help us address how media are embedded in the interlocking fabric of social and cultural life" [Couldry 2004, p. 129].

\section{Diverging definitions and mobilizations of power within analysis}

The conceptions and analysis of power by mediatisation theories and cultural studies seem to differentiate in regard to their diverging understanding of culture. As presented earlier, definition and use of power characteristic of the works inspired by cultural studies developed in American and Canadian academic fields is largely based on its Foucaldian conception. Power as defined by Foucault [1980] is crossing the social field, producing discourses that render intelligible specific objects of knowledge. This definition of power does not understand it as having any center, or being possessed by someone or any specific entity, no more that it is associated with the idea of state power as the only regulator of the social field. It rather produces the conditions of possibility that allows what could exist and be practiced or understood within a given socio-cultural context. These specific objects of knowledge, which are understood as "truth", produce and inform the social field for a given period and are produced by power struggles.

This definition of power allows to question different forces that are struggling and informing the cultural practice. Culture is, therefore, reproduced through practice which embodies and materializes what is structuring or informing it. It then may be conceived as the location of power struggles that allows the existence of some practices rather than others, practices that are not limited to representations. It also includes daily routines, 
institutional organisation and practices, economic or political activities, and more, all of it articulated by and within those power struggles that inform and allow their existence.

This conception of power differs from the original English developments of cultural studies (we can think of Birmingham Centre, for example) where several analyses focused on the selection and organisation of signs and significations constitutive of power struggles. Power is related here to Gramsci's hegemony concept and Althusser's notion of ideology which, "[t]raditionally within cultural studies [...] has been deployed to refer to ideas that justify the power of ascendant groups, though it can be used to suggest the justifying ideas of all social groups" [Barker 2004, p. 162].

As studies that conceptualize and analyze media in its relation to culture and society have become more salient in the last decade, theories inspired by the concept of media cultures were developed in France. Inspired by the development of cultural studies for its interest in the analysis of power, theoreticians mobilizing the media cultures' concept also worked to replace media at the centre of other practices, going beyond deterministic analyses of media. However, the analyses they propose are inspired by the definition of power in terms of ideological and hegemonic struggles and are mainly interested by the production of signification and representations. By doing so, they neglect to consider structures and relations that allows and organise these representations, central to a cultural analysis approach inspired by Williams who tried to understand it within its production conditions: "culture is not just a matter of representations and consciousness but of institutional practices, administrative routines and spatial arrangements that are manifestations of power" [Baker 2004, p. 162]. This is why the analysis works inspired by the media cultures' concept have been set aside from the present theoretical dialogue between cultural studies and mediatization theories, in their aim to question the power relations and struggles that inform the transformations that occur within media, culture and society.

It is important to note that a major distinctive point from the cultural studies is that within mediatization studies, even if some analyses may be inspired by Williams' definition of culture, the concept is not mobilised in such a way to understand its constitutive practices. Rather, these theories focus on the transformations engendered by the ongoing penetration of media in the practices and processes constitutive of the social field.

For example, Couldry has suggested in 2004 the development of a paradigm of media as practice which would aim to study practices as oriented toward the media and hence, its role in the organisation of constitutive practices of social world. Couldry seeks to question the use of media by people, the practices related to its use, considering media neither as texts nor objects, but rather as a whole set of practices that it informs, orients and organizes by its very existence:

This question, as I have suggested, cuts deeper than our sense of how it feels to live in a media-saturated world, since it covers both cognitive and emotional dimensions to how practices 
are ordered; and in turn, through the link with cognitive questions (ways of thinking and categorising the world), it links to the question of how practices (possibilities of action) are differentially ordered for those with ready access to media resources (whether as media producers or as privileged media sources) and for those without [Couldry 2004, p. 129].

This approach is interesting as it is a good illustration of the intent of mediatization theories to analyse power in terms of "effects". These "effects" need not to be understood in the way proposed in the analysis inspired by theories of media effects, but rather in the way it participates in producing and organizing the social field, media not being the only ones leading those transformations. In this non-media-centric perspective, other meta-processes such as globalization or individualization, for example, might be expressed in the transformations that inform media and communication practices and processes.

Practices are, therefore, not the site of negotiation of power struggles as in the case of cultural studies: the analysis mostly resides in highlighting their participation to "determine" the social field, in a co-constitutive process of interrelation within the context in which they occur. For example, Camilla M. Reestorff [2014], inspired by mediatization studies, amongst other theoretical frameworks and theoreticians, tried to grasp an understanding of the Femen movement as the result of an assemblage of human and non-human actors, mentioning legislative system and Facebook as an example of forces contributing to its constitution. She understands the movement as being informed and produced by and within a context characterized by the omnipresence of the media which participate in orienting the activists' actions. As such, Femen are seen as "successful in facilitating collective events that are staged in a manner that makes their activist imaginary spreadable" [Reestorff 2014, p. 493]. Mediatization theories help Reestorff to understand how media inform the practices, not only from activists themselves, but from other parties involved in the production of this collective imaginary such as members of the public, police officers or journalists. This conceptual frame work allows also to think about how the very existence of the media and potential effects render the existence of the movement possible.

An analysis of the same phenomenon conducted through cultural studies' lens allows to ask different questions: How these discourses and practices contribute to producing a particular relation to the body informed by, among other things, gender issues? How can we understand public speaking, how it is authorized, what it produces? How can it be understood in the actual context, characterised by the omnipresence of the media which contribute to producing and orienting practices? How can we understand the practices of different stakeholders involved in the event? How does it contribute to the production of a particular relation to the other, particularly in the context of a society characterised by the multiplication of bodies' monitoring and control techniques? These are the types of questions that could orient an analysis inspired by cultural studies and that would highlight the different 
power struggles that are at stake within the practices and discourses constitutive of such a movement.

This "media as practice" paradigm proposal from Couldry brings us to rethink the media, inspired by the definitions of culture and practice as presented by Williams. Could (and should) the media as cultural practice be analysed in its relation to other practices and relations constitutive of culture? Could it be the point of departure of an analysis inspired both by mediatization theories and cultural studies? In my opinion, we should agree with Sonia Livingstone, who referred to Williams and insisted on the necessity for researchers of the field to expose the naturalized work of mediation, highlighting the fact that mediation does not simply reflect reality, but rather contributes to producing it:

Whatever our politics regarding these relations of power and whether or not we seek to contest them, the enterprise of revealing the ways in which their operation is mediated indeed seems an appropriate ambition for those who believe media and communications to be ever more crucial in today's world - in short, for those who seek to explore the possible and actual mediation of everything [Livingstone 2009, p. 13].

By analysing what constitutes media practices and media communicative actions, it might be possible to grasp the changes informing the broader socio-cultural contexts and modulating the constitution of culture as the realm of our shared and constructed meanings. Media practices may then be observed in what they embody and produce in the sense of constitution of reality, both, at the same time, modulating and expressing the power struggles that come into play by and within them.

\section{Complementary approaches?}

The reconciliation suggested here presents interesting points of tension and convergence between the developments of cultural studies in America and the cultural perspective of mediatisation studies. After having located the theoretical point of view adopted within both fields, it has been necessary to develop and compare their definitions and mobilization of "culture" and "media", to see how both are intertwined with and convey different definitions of power. This dialogue has been put to the forefront with the hope that it may encourage further discussions and relevant theoretical avenues for critical research located within both fields. Thinking about this possible interplay lets me foresee the possibility of questioning objects, processes and phenomena in a critical perspective, but informed by a context produced and characterised by the omnipresence of the media. This would allow researchers to question the power struggles that are negotiated through practices themselves, without neglecting the consideration that most of these practices are made by or within media. 
Hepp and Krotz [2011] have proposed an interesting analytical approach that would be centered around what is being called "mediatization worlds", a form of analysis that would be situated, focused on the way individuals experience and transform their communication, molded by media, in daily life. This kind of situated analysis would allow access, to quote Hepp and Krotz, to "a certain binding intersubjective knowledge inventory, with specific social practices and cultural thickening" [Hepp and Krotz 2011, p. 146] and, therefore, to the significations and cultural practices interrelated to media transformations as "Mediatized worlds are the everyday concretization of media societies and media cultures" [idem, p. 146]. It appears to me to be a relevant avenue to actualize a critical lens inspired by the open dialogue between cultural and mediatisation studies. However, throughout any analysis emerging from the reconciliation of both fields, there is a need to take into account their different conceptualizations of power. This theoretical contextualisation is necessary to appropriately question the very existence of cultural and media practices as much as what they create, in a context produced, transformed and informed by the omnipresence of media.

\section{Bibliography}

Barker, C. (2004). The Sage Dictionary of Cultural Studies, London: Thousand Oaks, CA: Sage Publications, http://www.123library.org/book_details/?id=38 [access : 10.04.2017].

Bolin, G. (2014). Institution, Technology, World: Relationships Between the Media, Culture, and Society, [in:] K. Lundby (ed.), Mediatization of Communication, vol. 21, Berlin: De Gruyter Mouton.

Carey, J.W. (1989). Communication as Culture: Essays on Media and Society, Boston: Unwin Hyman.

Cervulle, M., Quemener, N. (2015). Cultural Studies: Théories et méthodes, Paris: Armand Colin. Couldry, N. (2004). Theorising Media as Practice, Social Semiotics, vol. 14, no. 2, pp. 115-132.

Foucault, M. (1980). Power/Knowledge: Selected Interviews and Other Writings, 1972-1977, Brighton: Harvester Press.

Grossberg, L. (1996). Contribution à une généalogie de l'état des Cultural Studies. La discipline des communications et la réception des Cultural Studies aux Etats-Unis, [in:] A. Claustres, F. Jaouën (eds.), Le tournant populaire des Cultural Studies: L'histoire de l'art face à une nouvelle cartographie du goût (1964-2008) (Vol. Towards a Genealogy of Cultural Studies: The Discipline of Communication and the Reception of Cultural Studies in the United States, Dijon: Les Presses du Réel, pp. 219-242.

Grossberg, L. (2010). Cultural Studies in the Future Tense, Durham: Duke University Press.

Hall, S. (1980). Cultural Studies: Two Paradigms, Media, Culture \& Society, vol. 2, no. 1, pp. 57-72, http://doi.org/10.1177/016344378000200106

Hepp, A. (2012). Mediatization and the 'Molding Force' of the Media, Communications, vol. 37, pp. 1-28.

Hepp, A. (2013). Cultures of Mediatization, Cambridge, UK-Malden, USA: Polity Press. 
Hepp, A., Hjarvard, S., Lundby, K. (2015). Mediatization: Theorizing the Interplay Between Media, Culture and Society, Media, Culture \& Society, vol. 37, no. 2, pp. 314-324, http://doi.org/10.1177/0163443715573835

Hesmondhalgh, D. (2008). Industries culturelles et cultural studies, [in:] H. Glévarec, E. Macé, E. Maigret (eds.), Cultural Studies. Anthologie, Paris: Armand Colin, pp. 275-293.

Hjarvard, S. (2008). The Mediatization of Society, Nordicom Review, vol. 29, no. 2, pp. 105-134. Hjarvard, S. (2013). The Mediatization of Culture and Society, New York: Routledge.

Hjarvard, S., Nybro Petersen, L. (2013). Mediatization and Cultural Change, Society of Media Researchers in Denmark, no. 54, pp. 1-7.

Krotz, F. (2009). Mediatization: A Concept with Which to Grasp Media and Societal Change, [in:] K. Lundby (ed.), Mediatization: Concept, Changes, Consequences, New York: Peter Lang.

Krotz, F., Hepp, A. (2011). A Concretization of Mediatization: How 'Mediatization Works' and Why Mediatized Worlds Are a Helpful Concept for Empirical Mediatization Research, Empedocles: European Journal for the Philosophy of Communication, vol. 3, no. 2, pp. 137-152.

Livingstone, S. (2009). On the Mediation of Everything, Journal of Communication, vol. 59, no. 1, pp. 1-18, http://doi.org/10.1111/j.1460-2466.2008.01401.x

Lundby, K. (2014). Mediatization of Communication, Berlin: De Gruyter Mouton.

Maigret, É. (2009). "Médiacultures» et coming out des cultural studies en France, Cahiers de Recherche Sociologique, no. 47, pp. 11-21.

Martín-Barbero, J. (2002). Des médias aux médiations: Communication, culture et hégémonie, Paris: CNRS Éditions.

Neveu, É. (2008). Les voyages des cultural studies, L'Homme, no. 187-188, pp. 315-341.

Reestorff, C.M. (2014). Mediatised Affective Activism: The Activist Imaginary and the Topless Body in the Femen Movement, Convergence: The International Journal of Research into New Media Technologies, vol. 20, no. 4, pp. 478-495, http://doi.org/10.1177/1354856514541358

Sawchuk, K. (2013). Tactical Mediatization and Activist Ageing: Pressures, Push-Backs, and the Story of RECAA, MedieKultur: Journal of Media and Communication Research, vol. 29, no. 54, p. 18.

Williams, R. (1961). The Long Revolution, New York: Columbia University Press.

Williams, R. (1975). Television: Technology and Cultural Form, New York: Schocken Books.

Williams, R. (1981). Culture, London: Fontana Press.

Williams, R. (2010). Base et superstructure, Culture et matérialisme, http://newleftreview.org/I/82/ raymond-williams-base-and-superstructure-in-marxist-cultural-theory [access: 10.04.2017]. 